Rewiew

\title{
MULTIPLE PREGNANCY AND BIRTH: TWINS, TRIPLETS AND HIGH-ORDER MULTIPLES. OVERVIEW
}

\author{
S. Lazarov, L. Lazarov, N. Lazarov \\ Department of Obstetrics and Gynecology, Medical Faculty, Trakia University, Stara Zagora, Bulgaria
}

\begin{abstract}
Multiple gestations are high risk pregnancies which may be complicated by prematurity,low birthweight, pre-eclampsia, anaemia, postpartum haemorrhage, intrauterine growth restriction, neonatal morbidity and high neonatal and infant mortality. There are more multiple births today in part because more women are receiving infertility treatment, which carries a risk of multiple pregnancy. They are many risk factors for multiple pregnancy such as: race, heredity, maternal age and pregnancy history as well as fertility drugs and assisted reproductive technology(ART). The frequency of twins increases with maternal age and number of pregnancies. Multiple pregnancy is more common in women who utilize fertility medications to undergo ovulation induction or superovulation. Assisted reproductive technology $(A R T)$ procedures such as in vitro fertilization (IVF) also contribute to the increase in the multiple birth rate. The risk of multiple pregnancy increases as the number of embryos transferred increases.
\end{abstract}

Key words: multiple pregnancy, heredity, fertility drugs, ART

\section{INTRODUCTION}

When in the uterus are developing more than one baby we talk about multiple pregnancy. When two eggs are fertilized by two sperm pregnancy from the outset it consists of two fetuses with their pridatatsi- membranes, placenta). Such a twin pregnancy is dizygotic twinning(DZ). When one kontseptus obtained by the merger of one egg and one sperm at a later stage splits and forms two fetus - such pregnancy call monozygotic (MZ) or identical.The ratio $\mathrm{DZ} / \mathrm{MZ}=2: 1 \mathrm{c}$ most developed countries.

There are various factors that predispose to multiple pregnancies. While DZ is considered as a variant of the norm, the $\mathrm{MZ}$ is the boundary of the pathological, since the separation of the fetus is never perfect. If they remain partially fused to certain body parts it results double malformations. $(1,2)$.

Multiple gestations are high risk pregnancies which may be complicated by prematurity,low birthweight, pre-eclampsia, anaemia, postpartum haemorrhage, intrauterine growth restriction, neonatal morbidity and high neonatal and infant mortality.

Multiple births are much more common today than they were in the past. $(3,4)$
According to the US Department of Health and Human Services, the twin birth rate has increased by over $75 \%$ since 1980 , and triplet, quadruplet, and high-order multiple births have increased at an even higher rate (5). There are more multiple births today in part because more women are receiving infertility treatment, which carries a risk of multiple pregnancy.

- The number of treatment-related pregnancies with triplets or more has decreased dramatically. Also, more women are waiting until later in life to attempt pregnancy, and older women are more likely than younger women to get pregnant with multiples, especially with fertility treatment. Although major medical advances have improved the outcomes of multiple births. Multiple births still are associated with significant medical risks and complications for the mother and children. In this review we dicust how and why multiple pregnancies occur and the unique issues associated with carrying and delivering a multiple pregnancy. (6)

\section{TWINS-THE MOST COMMON MULTIPLE}

There are two types of twins: identical and fraternal (non-identical). 
Identical twins occur when a single embryo, created by the union of a sperm and an egg, divides into two embryos. Each embryo is monozygotic, genetically identical, and both will be the same sex. Depending on when the division occurs, identical twins may have separate placentas and gestational sacs, or they may share a single placenta but have separate sacs. In rare cases, identical twins may be in the same amniotic sac.

Non-identical twins occur when two separate eggs are each fertilized by a separate sperm. The two embryos that result are dizygotic, not genetically identical, and can be the same or different sex. Most of the time, this is the type of twinning that occurs from assisted reproduction procedures.

\section{The "Vanishing Twin Syndrome"}

About $1 / 2$ to $2 / 3$ of twin pregnancies result with the birth of a one baby, the other twin died. The other twin either is absorbed in the first 10 weeks "Vanishing twin syndrome." or discovered during the birth as "faetus papyraceus". $(6,7)$

Sometimes, very early in a twin pregnancy, one of the fetuses "disappears." This is referred to as the "vanishing twin syndrome." Even after ultrasound has shown heart movement in twins, spontaneous loss of one of the fetuses occurs in up to $20 \%$ of twin pregnancies. Spontaneous losses are even higher in triplet and quadruplet pregnancies. A fetal loss rate of $40 \%$ may occur in pregnancies with triplets or more. When a fetus is lost in the first trimester, the remaining fetus or fetuses generally continue to develop normally, although vaginal bleeding may occur.

- Ultrasound examinations performed early in the 5th week of pregnancy occasionally may fail to identify all fetuses. An "appearing twin" may be found after the 5th week in nearly $10 \%$ of non-identical twin or multiple pregnancies and in over $80 \%$ of cases of identical twins. After 6 to 8 weeks, ultrasound should provide an accurate assessment of the number of fetuses. $(6,8)$

This case-control study compared the perinatal outcome of assisted reproduction pregnancies of the VT syndrome with that of assisted reproduction singletons. It was found that pregnancies diagnosed with the VT syndrome carry a higher rate of adverse obstetric outcomes. Moreover, the obstetric outcomes of the VT pregnancies in certain aspects, such as gestational age at delivery and the rate of preterm deliveries, were found to be similar to twin pregnancies. The present study found that
$4 \%$ of singleton deliveries after assisted reproduction treatment originated in twin pregnancy (3). This figure is similar to $6 \%$ reported by Shebl et al. (2008). Other groups have reported higher rates (up to 30\%) of single embryonic loss in pregnancies commencing with twins (Sampson and de Crespigny 1992; Pinborg et al., 2005, 2007). Regarding the obstetric outcomes of pregnancies diagnosed with the VT syndrome, the data support conclusions made by others and reviewed recently (van Oppenraaij et al., 2009). This review, performed on behalf of the European Society for Assisted Reproduction and Embryology Special Interest Group for Early Pregnancy (SIGEP), demonstrated an increase in adverse obstetric outcome after the VT/triplet phenomenon. It was postulated that this might be due to early implantation crowding, resulting in an unfavourable implantation site with uteroplacental insufficiency. It is of note, however, that when comparing the present work with that of others, different definitions have been used for preterm delivery. While in the present study it was defined as birth occurring before 34 weeks gestational age, others defined it as earlier than 37 weeks (Pinborg et al., 2005; Shebl et al., 2008), and while extreme preterm delivery is defined here as birth occurring earlier than 28 weeks gestational age, others have defined it as earlier than 34 weeks (Shebl et al., 2008) or 32 weeks (Pinborg et al., 2005). Shebl and coauthors demonstrated a higher risk for lower birth weights and small for gestational age newborns in singleton deliveries of VT pregnancies in a study of 46 cases (Shebl et al., 2008). Mean birth weight of 2876 versus 3249 $\mathrm{g}(\mathrm{P}=0.0004)$ were demonstrated for cases.

They concluded that IVF singletons from VT gestations have a higher risk of being SGA than singletons from a single gestation and that the higher the gestational age at the time of vanishing, the higher the risk that the surviving newborn will be SGA. without the VT syndrome. These results suggest that the perinatal outcomes of VT pregnancy resemble twin pregnancy more than singleton pregnancy. In spite of the disappearance of one of the pair, the course of the rest of the pregnancy is still closer to twin pregnancy than to regular singleton pregnancy. Opposing conclusions were brought forward by others. La Sala demonstrated similar obstetric outcomes for survivors of the VT syndrome, irrespective of the mode of assisted reproduction conception (La Sala et al., 2006). Birth weights as well as the proportion of low birth weight babies and very low birth weight 
babies were not statistically different. Explanations for worse obstetric outcomes in VT syndrome have been discussed in the literature (5). Early demise of one twin may in itself affect the surviving co-twin (Shebl et al., 2008). Other proposed mechanisms are infection (although both twins should be affected), and disturbed placental circulation of blood shunting through inter-twin vascular anastomoses, especially in monochorionic twins (La Sala et al., 2006). Chasen et al. demonstrated a higher rate of pre-eclampsia in pregnancies with spontaneous reduction before 14 weeks of gestation. $(5,9)$

\section{Risk Factors for Multiple Pregnancy}

Naturally, twins occur in about one in 250 pregnancies, triplets in about one in 10,000 pregnancies, and quadruplets in about one in 700,000 pregnancies. The main factor that increases the chances of having a multiple pregnancy is the use of infertility treatment, but there are other factors. $(10,11,12)$.

The race, age, heredity, or history of prior pregnancy does not increase your chance of having identical twins but does increase your chance of having fraternal twins. Infertility treatment increases your risk of having twins, both identical and fraternal. $(13,14)$.

Race. The overall rate of twins for all races in the United Statees is around 33 per 1,000 live births. Black and non-Hispanic white women have similar rates of twinning, while Hispanic women are less likely.

Heredity. The mother's family history may be more significant than the father's. Nonidentical twin women give birth to twins at the rate of 1 set per 60 births. However, nonidentical male twins father twins at a rate of 1 set per 125 births.

Maternal age and prior pregnancy history. The frequency of twins increases with maternal age and number of pregnancies. Women between 35 to 40 years of age with 4 or more children are 3 times more likely to have twins than a woman under 20 without children. (15, 6, 17).

Maternal height and weight. Non-identical twins are more common in large and tall women than in small women. This may be related more to nutrition than to body size alone. During World War II, the incidence of non-identical twinning decreased in Europe when food was not readily available.

Fertility Drugs and Assisted Reproductive Technology. Multiple pregnancy is more common in women who utilize fertility medications to undergo ovulation induction or superovulation. Of women who achieve pregnancy with clomiphene citrate, approximately $5 \%$ to $12 \%$ bear twins, and less than $1 \%$ bear triplets or more. Use of drugs to cause superovulation has caused the vast majority of the increase in the multiples. (5, 18-21).

Approximately $30 \%$ of pregnancies resulting from gonadotropins are multiples. While most of these pregnancies are twins, up to $5 \%$ are triplets or greater due to the release of more eggs than expected.

Assisted reproductive technology (ART) procedures such as in vitro fertilization (IVF) also contribute to the increase in the multiple birth rate. The risk of multiple pregnancy increases as the number of embryos transferred increases. $(3,7,22-29)$.

\section{DURATION OF MULTIPLE PREGNANCIES}

The duration of a normal singleton pregnancy ranges from 37 weeks to 42 weeks from the time of the last menstrual period. Twin pregnancies occasionally progress to 40 weeks but almost always deliver early. As 6 the number of fetuses increases, the expected duration of the pregnancy decreases $(1,4)$. The average duration is 35 weeks for twins, 33 weeks for triplets, and 30 weeks for quadruplets. (Table 1)

\begin{tabular}{llc}
\multicolumn{2}{c}{ Table 1. Average gestation age, type of pregnancy and birth weight } \\
TYPE OF & AVERAGE & AVERAGE BIRTH \\
PREGNANCY & GESTATIONAL & WEIGHT \\
& AGE AT TIME OF & \\
& DELIVERY & \\
Singleton & 38.6 weeks & $7.3 \mathrm{lb} .(3,300$ grams $)$ \\
Twin & 35 weeks & $5.1 \mathrm{lb} .(2,300$ grams $)$ \\
Triplet & 32 weeks & $3.7 \mathrm{lb} .(1,660$ grams $)$ \\
Quadruplet & 30 weeks & $2.9 \mathrm{lb} .(1,300$ grams $)$
\end{tabular}

(American society for reproductive medicine. Multiple pregnancy and birth: twins, triplets and high order multiples, 2012) 


\section{CONCLUSION}

The objective of infertility treatment is the birth of a healthy child. In a small percentage of patients, treatment results in multiple pregnancy that may place the mother and the babies at increased risk for an unhealthy outcome. Since multiple pregnancies and their complications are an inevitable risk of fertility therapies, education about these risks is crucial prior to treatment. Ultimately, prevention is the key to reducing the risk of multiple pregnancy.

\section{REFERENCES}

1. N.Vassillev. Manuel of Obstetrics Al. Hadjiev, N.Vassilev , 79-80. 1998.

2. G. Salamalekis1, V. Sioulas1, S. Mourtzakis2, et al. Twin Pregnancies In Older, Primiparous Women: Perinatal Outcomes. 1-st World Congress - Twin pregnancy- a global perspective. P 94. 2009.

3. Human reproduction, Multiple gestation pregnancy, vol.15 no.7 pp. 1856-1864, 2000.

4. G. Paladi, L. Tautu, U. Tabuica Multiple Gestation. 1-st World Congress - Twin pregnancy- a global perspective. P 80 . 2009.

5. Pinborg, O. Lidegaard, N.Freiesleben et al. Consequences of vanishing twins in IVF/ICSI pregnancies. Human reproduction vol.20, no10, pp. 2821-2829, 2005.

6. American Society For Reproductive. Medicine, Multiple Pregnancy and Birth: Twins, Triplets and High-order Multiples. A Guide for Patients ( Revised 2012).

7. D. Freitas, I. Pestana, T. Loureiro, T. Rodrigues. Hospital de São Joa o, Porto, Portugal. A Type Of Conception And Perinatal Outcomes. 1-st World Congress Twin pregnancy - a global perspective, P37. 2009

8. J. Michal Simchen, A. Wiser, E. Schiff, A. Shulman. The Aged Uterus - Multifetal Pregnancy Outcome After Ovum Donation In Older Women. 1-st World Congress Twin pregnancy - a global perspective, P99. 2009

9. Delbaere, H. Verstraelen, S.Goetgeluk et al. PERINATAL OUTCOME OF TWIN PREGNANCY IN WOMEN OF ADVANCED AGE. 1-st World Congress Twin pregnancy- a global perspective. 2009.

10.A. Lebre, V. S. Soares, M. Branda et al. SPONTANEOUS QUADRIPLET PREGNANCY: WHERE IS THE LIMI1-st
World Congress - Twin pregnancy- a global perspective, P 57. 2009.

11.A. Lebre, S. Azevedo, A. Gouveia, M. R. Rodrigues, R. Agarinho. Management Of Twin Delivery:Spontaneous Vs. Intentional Vaginal Delivery. 1-st World Congress Twin pregnancy - a global perspective. 2009.

12.M. Berisavac, M. Terzic, R. Argirovic, N. Markovic, J. Dotlic Route Of Delivery And Outcome Of TwinPregnancies Conceived After Ivf/Et Procedure. 1-st World Congress - Twin pregnancy- a global perspective, P13. 2009.

13.V. Michalitsi, G.M. Макрис, V. Stathopoulou, C. Patsouras,D. Cassanos, E. Salamalekis Outcome Of Twin Pregnancies After Spontaneous Conception And After Ivf. The Greek Experience. 1-st World Congress - Twin pregnancy- a global perspective. P69, 2009

14.I. Pestana, T. Loureiro, A. Almeida, L. Mota, M. Pinho, I. Rocha, R. Maria Rodrigues, A. Cunha,T. Rodrigues the Effect Of Mode Of Delivery On Neonatal Outcome Of Monochorionic Diamniotic Twins. 1-st World Congress - Twin pregnancy - a global perspective, P83. 2009.

15.P. Velebil, WHO Collaborating Center, Institute for the Care of Mother and Child, Department of Obstetrics, Prague, Czech Republic.Perinatal Results Ofmultiple Pregnancies In The Czech Republic During 2004-2008. 1-st World Congress - Twin pregnancy- a global perspective. P114. 2009.

16.I. Blickstein; Kaplan Medical Center, Rehovot, Israel. The Frequency, Secular Trends, Geographic Differences And Disease Burden Attributed To Multiple Gestation. 1-St World Congress - Twin pregnancy- a global perspective. P22. 2009.

17. Sabine Anthonya, Gert W. Jacobusseb, Karin M. Et al. Do differences in maternal age, parity and multiple births explain variations in fetal and neonatal mortality rates in Europe? Results from the EuroPeristat project. Paediatric and Perinatal Epidemiology; 23: 292-300. 2009.

18.C. Allen, S. Bowdin, F. Harrison et al. Pregnancy And Perinatal Outcomes After Assistedreproduction: A Comparative Study. 1-st World Congress - Twin pregnancy- a global perspective. 2009.

19.A Benny Almog, Ishai Levin, Israel Wagman, Rita Kapustiansky, et al. Adverse obstetric outcome for the vanishing twin 
20.syndrome. 1-st World Congress - Twin pregnancy - a global perspe 2009.

21.Fung Yee Chan, Centre for Maternal Fetal Medicine at the Mater Mothers' Hospital, University of Queensland. Obstetric implications of multiple gestation.

22.E. Vasario, S. Arduino, V. Borgarello, C. Bossotti, Massarenti, M. Biolcati, T. Todros Outcome Of Spontaneous Versus IVF Twin Pregnancies. Fertility clinicdept. Obstetrics/Gynecology, Hospital Erasme and Human reprod.research lab., Belgium

23. S. Raspopovic, V. Miketic, D. natalic Quadruplets After Ivf/Et Procedure Pregnancy Management And Outcome -Case Report. 1-st World Congress - Twin pregnancy - a global perspective. 2009.

23. I. Rovelli, G. Prandi, F. Giuliani, A. Coscia, E. Bertino, E. Garzena, C. Peila, L. Occhi, C. Fabris, Neonatal Outcomes In Triplet Pregnancies: Assisted Reproduction Versus Spontaneous Conception. 1-st World Congress - Twin pregnancy - a global perspective. P92. 2009.

24.Sarah McDonald.Describing the present.Prvalence of multiple pregnancies in Canada and the contribution of assisted reproduction treatments to the problem. Prevalence of multiple pregnancies in Canada. Reproductive Bio Medicine Online.
LAZAROV S., et al.

Vol.14 No 6, 2007, pp. 773-790

25.Anja Pinborg, Anne Loft, Lone Schmidt, et al.. Maternal Risks And Perinatal Outcome In A Danish National Cohort Of 1005 Twin Pregnancies: The Role Of In Vitro Fertilization. Acta Obstet.Gynecol. Scand.

26. Y. Englert, S. Yaacoub, S. Emiliani, A. Delbaere Assisted Reproductive Technologies As A Cause Of Multiple Gestation. 1-st World Congress - Twin pregnancy - a global perspective. 2009.

27.M. de Freitas1, A. F. A. Siqueira,

A. M. Conceic, a o Segre 2 children Born After Assisted Reproduction Techniques: Maternal Aspects And Perinatal Results. 1st World Congress - Twin pregnancy- a global perspective. P20. 2009.

28. C. F. Florescu, R. Nicula, D. Diculescu, et al. D. Sprinjan. Comparative Study Of Obstetrical Complications And Perinatal Outcomes In IVF Vs. Spontaneously Conceived Twin Pregnancies. 1-st World Congress - Twin pregnancy- a global perspective. P34. 2009.

29. M. Terzic, M. Berisavac, J. Dotlic, J. Micic. Vaginal Twin Delivery: Course Of Labour And Perinatal Outcome . 1-st World Congress - Twin pregnancy- a global perspective. P106, 2009. 